\title{
AN EXPERIMENTAL STUDY OF FACTORS UNDERLYING DIFFERENTIAL ECOSYSTEM RECOVERY FROM ACIDIFICATION OF UPLAND WATERS
}

\author{
BRAY, R. \\ David Livingstone Centre for Sustainability, University of Strathclyde, \\ Glasgow, G1 1XQ, Scotland, UK \\ (phone: +44-1369-810222) \\ *Corresponding author \\ e-mail:Robert.Bray@strath.ac.uk \\ (Received $12^{\text {th }}$ February 2013; accepted $30^{\text {th }}$ November 2013)
}

\begin{abstract}
Many aquatic ecosystems continue to show the impact of acidification. Two factors that have been put forward to explain retarded biological recovery from aquatic acidification: geology and land-use (specifically, coniferous afforestation). The present study tests the hypothesis that afforestation is more significant than underlying geology in limiting recovery. Six streams were sampled using a $2 \times 3$ design with two types of underlying geology and three levels of afforestation. Results provide evidence for substantial chemical recovery but limited and uneven biological recovery. Statistical analysis suggested that both afforestation and geology had significant impacts on biological indicators, but geology had a greater impact on the richness of acid sensitive species. These results are discussed in relation to competing theories on factors underlying differential and retarded biological recovery.
\end{abstract}

Keywords: acidification, recovery, invertebrates, afforestation

\section{Introduction}

The acidification of surface waters continues to be a major threat to aquatic ecosystems, causing ecological simplification, the loss of acid-sensitive species and a reduction in biodiversity (UKAWMN, 2001). Acid Deposition was the first recognized example of major transboundary pollution (Schindler 1988) and an illustration of how scientific evidence of pollution impacts can influence policy making at a global level. International agreements to limit emissions, such as the 1979 Convention on Long Range Trans Boundary Air Pollution, have subsequently resulted in large decreases in emissions of sulphates (UKAWMN, 2001; Monteith and Evans, 2005).

The problems arising from Acid Deposition are, however, far from being solved. Although sulphate emissions have declined in Europe, they continue to rise globally (Bouwman et al., 2002), particularly in Asia (Monteith and Evans, 2005; Matsubara et al., 2009; Wei and Wang, 2005). Nitrate emissions have become relatively more important and there is evidence that nitrate saturation of vegetation and soils may lead to reacidification of some areas (UKAWMN 2001; Armbruster et al., 2003). Overall, acidification is still regarded as the foremost problem affecting biodiversity in surface waters of Northern Europe (Johnson and Angeler, 2010).

In Britain, however, there is evidence for substantial chemical recovery from aqueous acidification. Davies et al (2005) reported that analysis of water chemistry data in the UK over 15 years from 22 acid sensitive sites (lakes and streams) showed consistent trends in recovery, with sulphate and base cations declining. Monteith and Evans (2005), in a review of the United Kingdom Acid Waters Monitoring Network (UKAWMN results) concluded that there were widespread increases in $\mathrm{pH}$ and 
alkalinity, and decreases in $\mathrm{Al}^{3+}$ (Aluminium being mobilized by acidification: Wellburn, 1988; Mason, 1991; Csontos et al., 2012). Water sulphate levels had decreased, so that Nitrate levels became relatively more important. They added, however, that the effects of catchment soil and vegetation on recovery were little understood and required more research.

Biological recovery has, however, been much slower and more uneven than chemical recovery (Johnson and Angeler, 2010). Even where acid deposition has clearly decreased, recovery of some ecosystems has often been remarkably slow (Alewell et al., 2000). Clair and Hindar (2005) found evidence that restored communities were more unstable than those in unaffected areas, although effects on assemblage structure and food webs are little understood (Johnson et al., 1991; Lovett et al., 2009). The impacts of Climate Change may exacerbate acidification effects, especially on species close to their tolerance limits (Raddum and Fjellheim, 2002; SEPA, 2006). Overall, ecosystems may take many decades to recover to previous, uncontaminated states (Jenkins et al., 1998; Colls, 2002), and the biological outcomes are uncertain (Monteith et al., 2005). Some ecosystems may never return to their original state (Schindler, 1988; Clair and Hindar, 2005; SEPA, 2006). Aquatic acidification remains, therefore, a serious environmental problem with many unanswered questions (Ledger and Hildrew, 2005). Research into the conditions affecting recovery from acidification is as pertinent as ever.

One of the unresolved questions concerns the role of moderating variables such as underlying geology and land-use. There is general agreement that both are implicated in the impact of acid deposition on subsequent acidification: some bedrocks, such as granites, are base poor so that buffering cations are soon exhausted (UKAWMN, 2001). Similarly, there is widespread agreement that land-use - specifically levels of coniferous afforestation - also contributes to acidification (Mason, 1991; Puhr et al., 2000). Coniferous forest, particularly if older with continuous canopy, is especially effective at scavenging atmospheric pollutants (SEPA, 2006). However, there has been less research - and even less agreement - concerning the relative contributions of geology and afforestation to rates of recovery. Harriman et al. (2003), for instance, found some evidence that moorland and forest catchment showed similar responses to reductions in Sulphur deposition, but that forested sites had greater levels of toxic forms of Aluminium, and concluded that continued planting in acidified catchments may retard chemical and biological recovery. On the other hand, there is also evidence that the use of Critical Load methodology used by the Forestry Commission has been sufficient in preventing planting in sensitive areas, and that afforestation is not, therefore, responsible for significantly retarded recovery (Forestry Commission, 2003).

The Scottish Environmental Protection Agency (SEPA) has highlighted particular problems in the Galloway hills and west central Highlands of Scotland: fifty rivers and twenty lochs remained in poor ecological status because of acidification (SEPA, 2006). SEPA also noted that there may be significant variations in the extent of ecosystem recovery, and gave an illustrative example of the River Cree catchment area in the Galloway hills areas of South West Scotland. Within this river system, the Pulnagashel Burn showed evidence of steady recovery, with the number of acid-sensitive species increasing significantly from 1996 to 2004. In contrast, Cairnfore Burn, a nearby and similar stream, had shown no such recovery. The report commented that the reasons for such differences remained unclear, but SEPA suggested that interactions between underlying geology and land-use (degree of afforestation and planting/felling regimes). 
This study aims to explore the factors underlying these differences and, by extension, provide a broader explanatory framework for such differential recovery.

This study addresses the issue of the relative contributions of geology and land-use to retarded recovery using a balanced experimental design. Most previous research on recovery has either monitored a large number of dispersed sites (e.g. Monteith et al., 2005) or carried out detailed studies of one site (e.g. Collen et al., 2000). This research, in contrast, compared several adjacent watercourses simultaneously. The experimental design required that six upland streams were selected matched as closely as possible and being distinguished as follows: three catchments with predominantly granitic underlying bedrock, while the other three catchments lay on sedimentary rocks. Within each group of three, there three distinct levels of coniferous afforestation. The streams chosen were within the River Cree catchment, previously identified by SEPA as showing differential responses and which displays a variety of different underlying geological forms and land-usage. The main hypothesis tested was that catchment afforestation would have greater effects on chemical and biological recovery than geological factors.

\section{Method}

The River Cree system lies within the area of the Galloway hills in South West Scotland. This area has been identified as being particularly vulnerable to acidification and has therefore been the setting for several previous studies (Rendall and Bell, 2008). Geologically, the eastern part of the catchment is dominated by the igneous mass South of Loch Doon, featuring the Mullwachar $(692 \mathrm{~m})$ and Merrick $(843 \mathrm{~m})$ tops (Greig 1971). With regard to land-use, Dumfries and Galloway is one of the most afforested areas in Britain with approximately $25 \%$ tree cover, of which $93 \%$ is coniferous. Virtually all of this has been planted in the last century, particularly in the 1970s and 1980s; much of the coniferous forest is, therefore, now mature (thirty-five years or older). The dominant species is Sitka spruce (Picea sitchensis), with smaller amounts of Lodgepole pine (Pinus contorta), Scots pine (Pinus sylvestris), Norway spruce (Picea abies) and European Larch (Larix decidua). The river Cree is a designated salmonid fishery under the EC Freshwater Fisheries Directive (Environment Resources Management 2000).

Two areas of the Cree catchment, approximately $5 \mathrm{~km}$ apart, were selected on the basis of their solid (underlying) geology, using the British Geology Survey Solid Geology Map (UK North Sheet; $4^{\text {th }}$. Edition) 1:625000 scale:

1. West of Water of Minnoch: catchments in Ordivician Sedimentary formations of slates, shales and greywacke (less base-poor);

2. North of Water of Trool: catchments on Mullwacher-Merrick Igneous Intrusion; mainly granitic (more base-poor). (The Waters of Minnoch and Trool are both tributaries of the River Cree).

Both areas were within Forestry Commission Scotland (FCS) land, from whom permission to gain access to carry out this study was obtained. Catchment areas and percentage land-use for each stream were calculated using FC 1:10000 Forestry maps showing planting, felling and restocking details. Using this information, and following field visits, six first-order headwaters were identified as meeting the criteria. Three sites were identified in each of the two geological areas, and in each of the areas one had low afforestation $(<55 \%)$, a second had moderate afforestation $(60-70 \%)$ and a third with substantial afforestation $(>80 \%)$. Note that land that had been felled within three years 
was excluded from the calculation of amount of afforestation, as such land either would remain clear at the time of sampling or would have very young trees, which might not be implicated in increased scavenging effects.

The six sites identified are shown in Table 1 in relation to the experimental design.

Table 1. Experimental design and study sites

\begin{tabular}{c|c|c|c}
\hline & \multicolumn{3}{|c}{ Catchment land use: level of afforestation } \\
\hline Underlying geology & Low & Medium & High \\
\hline Granitic & $\mathrm{G}_{\mathrm{L}}$ & $\mathrm{G}_{\mathrm{M}}$ & $\mathrm{G}_{\mathrm{H}}$ \\
& Pulnabrick Burn & Pulnagashel Burn & Torr Lane \\
Sedimentary & $\mathrm{S}_{\mathrm{L}}$ & $\mathrm{S}_{\mathrm{M}}$ & $\mathrm{S}_{\mathrm{H}}$ \\
& Rowantree Burn & Minnoch Tributary & Black Burn \\
\hline
\end{tabular}

Sampling occurred at each of the six sites on two occasions during the spring (March - May). At each of these twelve visits, samples were collected from two locations within each site: one in a riffle area (erosional habitat) and one in a pool or margin (depositional habitat). In total, therefore, twenty-four measurements of each variable were taken ( $\operatorname{cix}$ sites $\times$ two visits $\times$ two locations per site). At each visit, on-site measurements were taken, samples collected for transport to the laboratory for subsequent analysis of anions, and samples taken for subsequent biological analysis.

On-site streamwater measurements were taken of $\mathrm{pH}$, Electrical Conductivity (EC), TDS (Total Dissolved Solids) and water temperature were measured using a Hanna HI98130 pH/EC/TDS/temperature meter. Dissolved Oxygen (DO) was measured using a VWR DO200 Portable Dissolved Oxygen instrument. Measures of EC, TDS, DO and water temperature were taken to compare the sites and test their homogeneity, to ensure that other inter-site comparisons were valid (Cleresci et al., 1998: 10.97).

Chemical analysis of Anions was conducted using a Dionex Ion Chromatography system, for chloride, phosphate, nitrate and sulphate levels using normal laboratory procedures (Cleresci et al., 1998).

Biological sampling was carried out at each visit to each site, samples being collected from riffle and pool areas, using three minute kick sampling (three separate one-minute periods), following standard methods (Rendall and Bell, 2008; Monteith et al., 2005). For identification, the procedure of Elliott et al. (1988) was used: samples were brought back to the laboratory and macroinvertebrates in target taxa identified, using a Brunel MX1 stereo microscope at $\times 20$ and $\times 60$ magnifications. Target taxa were Plecoptera, Odonata, Trichoptera, Neuroptera, Ephemeroptera, Hemiptera, and Coleoptera. Identification was made to species level where possible and, if not, to the next highest possible level (genus, family etc.). The number of individuals in each taxon was recorded. Identification was carri ed out using Elliot et al. (1988) and Kimmins (1950a) for Ephemeroptera, Hynes (1977) and Kimmins (1950b) for Plecoptera; Macan (1959) and Quigley (1977) for all other taxa. Acid Sensitive (AS) taxa were categorized using the SEPA Biological Index of Acidity (BIA) (Rendell and Bell, 2008). This classifies aquatic invertebrate taxa into three categories, dependent on their presence or absence in acidified water. List A of the BIA contains taxa generally absent below mean level pH 6.0 (most sensitive) and List B contains taxa generally absent below mean level pH 5.5 (moderately sensitive). All other taxa are regarded as not acid sensitive. 
The homogeneity of the six sites was tested using one-way Analysis of Variance (ANOVA). The main hypothesis was tested using two-way ANOVA, with the factors being land-use (three levels of afforestation: low, medium and high) and geology (two types: sedimentary and granitic). Chemical and biological responses were the dependent variables. Statistical tests were carried out using Minitab 15.

\section{Results}

On-site streamwater measurements are summarized in Table 2.

Table 2. On-site streamwater measurements results.

\begin{tabular}{c|c|c|c|c|c|c}
\hline & $\begin{array}{c}\text { Pulnabrick } \\
\text { Burn }\end{array}$ & $\begin{array}{c}\text { Pulnagashel } \\
\text { Burn }\end{array}$ & Torr Lane & $\begin{array}{c}\text { Rowantree } \\
\text { Burn }\end{array}$ & $\begin{array}{c}\text { Minnoch } \\
\text { tributary }\end{array}$ & Black Burn \\
\hline Designation & $\mathrm{G}_{\mathrm{L}}$ & $\mathrm{G}_{\mathrm{M}}$ & $\mathrm{G}_{\mathrm{H}}$ & $\mathrm{S}_{\mathrm{L}}$ & $\mathrm{S}_{\mathrm{M}}$ & $\mathrm{S}_{\mathrm{H}}$ \\
$\mathrm{pH}$ & 7.48 & 6.94 & 7.33 & 7.44 & 6.32 & 5.86 \\
$\mathrm{Temp}{ }^{\circ} \mathrm{C}$ & 7.15 & 8.85 & 8.75 & 10.75 & 9.30 & 11.25 \\
$\mathrm{EC} \mathrm{mS/cm}$ & 0.020 & 0.025 & 0.045 & 0.025 & 0.060 & 0.035 \\
$\mathrm{TDS} \mathrm{ppt}$ & 0.005 & 0.005 & 0.020 & 0.015 & 0.030 & 0.020 \\
DO ppm & 12.75 & 12.40 & 11.90 & 11.34 & 5.60 & 10.60 \\
\hline
\end{tabular}

In the samples taken at the 12 visits to the six sites, $\mathrm{pH}$ levels had a mean value of 6.89 with a range of 5.59 to 7.56 . Waters can be categorized as being acidic if the mean $\mathrm{pH}$ is less than 5.6 (Doughty 1990). By these criteria, only one stream on one visit could be termed acidic.

Analysis of variance was carried out to test the heterogeneity of the six sites with respect to water temperature, EC and TDS. This was not significant for water temperature $(\mathrm{F}=0.21 \mathrm{p}=0.948), \mathrm{EC}(\mathrm{F}=0.22 \mathrm{p}=0.939)$, TDS $(\mathrm{F}=0.68 \mathrm{p}=0.653)$ or $\mathrm{DO}(\mathrm{F}=0.96 \mathrm{p}=0.509)$. The only noticeable systematic variation between streams was the low DO level in the Minnoch tributary. There was therefore no other indication that the sites were ecologically dissimilar and it was therefore concluded that comparisons between sites in terms of invertebrate composition would be valid.

\section{Chemical analysis}

The summarized results for Anion analysis is given in Table 3. In all cases, four samples were taken at each site (two visits at two locations within each site site).

The slightly higher levels of chloride at sedimentary sites may be at least partly explained by increased marine influence at those sites (Gagkas et al., 2008, for instance, found a strong relationship between Chloride levels and distance from coast). Sulphate levels do show significant differences with respect to geology, land-use and their interaction, with the High-afforestation level granitic stream (Torr Lane) having much higher levels than all other sites. In the three sedimentary streams, however, sulphate levels slightly decrease as afforestation increases. 
Table 3. Mean concentrations and ranges of Chloride, Nitrate and Sulphate (all in $\mathrm{mg}^{-1}$ ) in streamwater samples from the six sites

\begin{tabular}{c|c|c|c|c}
\hline & & Chloride & Nitrate & Sulphate \\
\hline Pulnabrick Burn & $\mathrm{G}_{\mathrm{L}}$ & 4.09 & 2.21 & 1.69 \\
Pulnagashel Burn & $\mathrm{G}_{\mathrm{M}}$ & 6.87 & 2.08 & 1.79 \\
Torr Lane & $\mathrm{G}_{\mathrm{H}}$ & 6.91 & 7.46 & 4.77 \\
Rowantree Burn & $\mathrm{S}_{\mathrm{L}}$ & 9.23 & 3.87 & 2.11 \\
Minnoch Tributary & $\mathrm{S}_{\mathrm{M}}$ & 9.41 & 4.14 & 1.58 \\
Black Burn & $\mathrm{S}_{\mathrm{H}}$ & 9.03 & 1.69 & 1.47 \\
\hline
\end{tabular}

In terms of the absolute levels of the measures themselves, sulphate levels were lower than those found in some previous reports of acidified waters. Doughty (1990: 6), for instance, found a mean sulphate level of $4.58 \mathrm{mg} \mathrm{l}^{-1}$ in the six "normally acid" waters (mean pH 5.21) and $3.88 \mathrm{mg} \mathrm{l}^{-1}$ in 29 "frequently acid streams" (mean pH 6.01),


chloride, Doughty found means of $5.57 \mathrm{mg}^{-1}$ in normally acid streams and $6.14 \mathrm{mg}^{-1}$ in those frequently acid, compared with $7.58 \mathrm{mg} \mathrm{l}^{-1}$ in the six study streams. Nitrate levels found in this study were comparatively low. SEPA (2006) statistics show that almost $50 \%$ of all Scottish waters had nitrate levels higher than the $3.57 \mathrm{mg} \mathrm{l}^{-1}$ found in the six study sites. Overall, there is considerable evidence from these results that mean levels of chemical indicators have largely recovered from acidification in the study sites.

\section{Biological sampling}

A total of 19 different taxa were collected. Table 4 summarizes the results of biological sampling. Two visits at two locations for each site were made to give four samples per site.

Table 4. Biological sampling results

\begin{tabular}{c|c|c|c|c}
\hline & & Number of taxa & AS taxa & \% of AS taxa \\
\hline Pulnabrick Burn & $\mathrm{G}_{\mathrm{L}}$ & 4 & 0 & 0.0 \\
Pulnagashel Burn & $\mathrm{G}_{\mathrm{M}}$ & 7 & 1 & 14.3 \\
Torr Lane & $\mathrm{G}_{\mathrm{H}}$ & 8 & 0 & 0.0 \\
Rowantree Burn & $\mathrm{S}_{\mathrm{L}}$ & 11 & 4 & 36.4 \\
Minnoch Tributary & $\mathrm{S}_{\mathrm{M}}$ & 9 & 2 & 22.2 \\
Black Burn & $\mathrm{S}_{\mathrm{H}}$ & 5 & 0 & 0.0 \\
\hline
\end{tabular}

Invertebrates were unevenly distributed over the six sites. $72 \%$ of individuals came from two of the six sites, while $90 \%$ AS individuals came from just one site (Rowantree Burn). Seven of the twenty-four sample contained no AS individuals. Only one AS individual was found in the three granitic sites. The least afforested sedimentary site (Rowantree Burn) had $90 \%$ of the AS individuals. 


\section{Relationships between independent and dependent variables}

Table 5 summarizes the mean values of each level of the independent variables for each dependent variable (that is, level of afforestation and nature of underlying geology).

Table 5. Mean values for three levels of forestation (low, medium and high) and two types of geology (sedimentary and granitic) for each dependent variable

\begin{tabular}{c|c|c|c|c|c}
\hline & \multicolumn{3}{|c|}{ Land use - forestation } & \multicolumn{2}{c}{ Geology } \\
\hline Variable & Low & Medium & High & Sedimentary & Granite \\
\hline $\mathrm{pH}$ & 7.46 & 6.63 & 6.59 & 6.54 & 7.25 \\
Chloride $\left(m g l^{-1}\right)$ & 6.66 & 8.12 & 7.97 & 9.21 & 5.95 \\
Nitrate $\left(m g l^{-1}\right)$ & 3.04 & 3.11 & 4.57 & 3.23 & 3.92 \\
Sulphate $\left(m g l^{-1}\right)$ & 1.90 & 1.69 & 3.12 & 1.72 & 2.75 \\
Taxa & 3.13 & 3.13 & 2.00 & 3.17 & 2.33 \\
AS taxa & 1.00 & 0.38 & 0.38 & 1.08 & 0.08 \\
\hline
\end{tabular}

This data was subject to a two way Analysis of Variance. Table 6 summaries the results of two-way ANOVA tests (two types of geology and three levels of forestation land-use) for each dependent variable.

Table 6. Results for two-way ANOVA comparing dependent variables among land-use levels and geology types

\begin{tabular}{c|c|c|c}
\hline Dependent variable & Factor & F & P \\
\hline \multirow{3}{*}{$\mathrm{pH}$} & Land-use & 68.52 & $<0.001$ \\
& Geology & 107.72 & $<.001$ \\
& Interaction & 37.67 & $<.001$ \\
Chloride & Land-use & 0.18 & 0.839 \\
& Geology & 2.18 & 0.157 \\
& Interaction & 0.19 & 0.832 \\
Nitrate & Land-use & 0.44 & 0.654 \\
& Geology & 0.20 & 0.659 \\
& Interaction & 2.81 & 0.087 \\
Sulphate & Land-use & 9.41 & 0.002 \\
& Geology & 12.43 & 0.002 \\
& Interaction & 15.48 & $<.001$ \\
Taxa & Land-use & 1.96 & 0.170 \\
& Geology & 2.42 & 0.137 \\
& Interaction & 4.81 & 0.021 \\
AS taxa & Land-use & 2.88 & 0.082 \\
& Geology & 16.62 & 0.001 \\
& Interaction & 4.5 & 0.026 \\
\hline
\end{tabular}


Statistical analysis also showed that both geology and degree of afforestation were significantly associated with differences in number of individual invertebrates and number of AS individuals, with granitic bedrock and higher afforestation sites having lower numbers of both. ANOVA results were significant at the $0.1 \%$ level for these effects. Of the total number of benthic invertebrates found $72 \%$ were found in the two low- and medium-afforested sedimentary sites.

The other relationships between the two independent variables and the biological indicators followed the same pattern (granite and high forestation giving less biodiversity), but not at statistically significant levels. The interaction between geology and land-use was significant for all four biological variables. That is, high afforestation and granite combined tended to have a disproportionately high impact on biological diversity.

\section{Discussion}

These results provide strong evidence for the importance of both geology and landuse in biological recovery from acidification, separately and in interaction with each other. The three granitic sites and the most afforested sedimentary sites were low in terms of overall numbers of invertebrates and very low in numbers of AS taxa (only one individual in the sixteen samples taken at these four sites). In relation to total invertebrate abundance and also abundance of AS individuals land-use and geology have effects of approximately equal magnitude. However, with respect to the number of AS taxa, geology has a statistically significant effect while land-use (afforestation) does not.

These results can be compared to those of Rendall and Bell (2008) carried out for SEPA. They found only three sites, out of 42 sampled in Dumfries and Galloway that had no AS taxa present (7\%), compared to three of the six sites studied here. The most acidified sites in their study were often in upper parts of catchments and several of the sites most affected were within the River Cree system. By comparison, 24 out of the total of 42 sites had at least $10 \%$ AS taxa, and seven had more than $50 \%$. In this study, the Low- and Medium- afforested sedimentary streams (Rowantree Burn and Minnoch tributary) had $36.4 \%$ and $22.2 \%$ of AS taxa respectively. This suggests that in the four most acidified sites in this study biological recovery was very retarded, whereas in the other two streams recovery had proceeded well. There is evidence that low afforestation together with sedimentary bedrock facilitates biological recovery, while either high afforestation or granitic geology leads to a significant retardation in recovery. A combination of both high afforestation and granitic bedrock is associated with very low recovery.

Within these clear and statistically significant patterns there are, however, some anomalies. Overall number of taxa increased with level of afforestation in granitic sites, for instance, and the Medium-afforestation site (Minnoch tributary) had somewhat more individuals than the Low-afforestation stream (Rowantree Burn). Given the degree of variation, however, in biological indicators, the discrepancies from expected levels are minor, as evidenced by the high levels of significance shown in the ANOVA tests.

There is evidence from these results that mean levels of the chemical indicators are in the normal, that is non-acidified, range. This would indicate that the chemistry of all six of these streams has largely recovered from acidification. Although afforestation is associated with lower $\mathrm{pH}$ and higher sulphate, the differences are not large. In contrast, 
biological indicators show that four of the six streams have low species richness and few or no AS species, together with low overall abundance of benthic invertebrates. This suggests that these four streams (all those on granitic bedrock and the sedimentary stream with high-afforestation) show very little biological recovery from acidification. For these biological indicators there are a number of strong relationships between species richness and overall abundance and both geology and land-use (level of afforestation). This supports the hypothesis that geology has the greatest impact on recovery from acidification rather more than the hypothesis that land-use is most important, although clearly both are important as is the interaction between the two.

Taken together there is, therefore, strong evidence to suggest that, while streamwater chemistry has largely recovered from acidification, biological recovery is much slower and that both geology and land-use (independently and in interaction) contribute to this, with geology being more significant in effecting richness of Acid Sensitive species. There are a number of possible explanations for this differential (between chemical and biological indicators) concerning geology and land-use.

\section{Explanations of differential recovery}

Monteith et al (2005: 96) put forward four types of hypothesis to explain the lag between chemical recovery and its biotic response:

1. The "linearity" hypothesis: that the relationship between chemical and biological variables is linear, but the former has not changed sufficiently;

2. The chemical "threshold" hypothesis: that the relationship is non-linear and a threshold must be reached before biological assemblage structure changes;

3. The "dispersal" hypothesis: that AS species disperse slowly back to acidified sites, causing time-lags;

4. The "community closure" hypothesis: that acidified ecosystems change their assemblage structure to a new equilibrium, which presents barriers to returning species.

In addition to these four explanatory frameworks it is possible to add another:

5. The "episodicity" hypothesis: that chemical-biological differentials can be explained in terms of infrequent but extreme events, so that sites that are prone to great fluctuations in acid deposition over time may have retarded recovery from acidification (Beverland et al., 1997; Jamieson, 1998). Each of these five hypotheses will be discussed in turn.

\section{The "linearity" hypothesis}

This hypothesis assumes that biota respond proportionately to changes in water chemistry. Monteith et al. (2005) cited some evidence that supports this, particularly for diatoms. The results of this study, however, show that chemical indicators have generally recovered to levels similar to those in waters that have never been acidified. This conforms to the results of recent studies on chemical recovery (Davies et al., 2005; Monteith and Evans, 2005), providing compelling evidence against the linear hypothesis. 


\section{The "Chemical threshold" hypothesis}

Monteith et al. (2005) suggested that this might be intrinsically more likely than the linearity hypothesis. They proposed that punctuated change would occur, with groups of taxa reappearing once certain chemical thresholds have been achieved. They cited some evidence from studies of macrophytes and fish. With regard to the latter, however, it might be that time lags are more related to trophic level than chemical threshold. That is, organisms higher in trophic level cannot reappear until those in lower trophic levels have become fully established.

The results of this study again would not agree with such a proposal, insofar as chemical recovery has proceeded to virtually normal levels.

\section{The "Dispersal" hypothesis}

The central idea of this hypothesis is that biological recovery will be limited by the maximum dispersal speeds of AS species returning to previously acidified sites. Elliot et al. (1988) summarized research on the dispersal of Ephemeroptera that showed that in some (but not all) species, adults flew upstream to lay eggs (thus compensating for downstream drift of eggs and larvae), but that these distance were large and were often dependent on wind direction. In other species, the larvae themselves can move upstream.

Monteith et al. (2005) presented evidence for the dispersal hypothesis from the UKAWMN studies. These showed that the two waters that showed greatest divergence between chemical and biological (macroinvertebrate) recovery both lay "in close proximity within the strongly acidified region of Galloway" ( $\mathrm{p} 98$ ). They suggested that it is feasible, therefore, that such areas would apply more "dispersal constraints", as the ecological sources for dispersal would likely to be more distant than in other sites. The two waters in question lie just to the East of the study sites, within the Merrick igneous area, so that their proposal is particularly relevant to this study. On the one hand, the two waters (Round Loch of Glenhead and Dargall Lane) quoted by Monteith et al are close (between 6 and $10 \mathrm{~km}$ ) to the three granitic sites used in the present study (which showed the least biological recovery), suggesting that dispersal might be a limiting factor throughout this area. On the other hand, the site with greatest biological recovery of the six (Rowantree Burn) is also isolated from other waters, being near the top of the catchment area for the River Cree on the Water of Minnoch tributary. Sites lower down the Water of Minnoch, which would presumably be closer to sources of macroinvertebrate dispersal, showed less biological recovery, with fewer species overall and fewer AS species. It would be difficult to explain this finding using the dispersal hypothesis, unless AS species found at the top of the catchment had 'leapfrogged' other streams.

There is, moreover, further evidence against the dispersal hypothesis. Bradley and Ormerod (2002), in their study of the biological recovery of Welsh streams, which had been limed, found that over a ten-year period many AS species reappeared at least once, but failed to become established. They argued that the results showed that AS species were able to reach previously acidified sites, but other factors were preventing them reoccupying the ecological niches that they had previously held. Masters et al. (2007) used malaise traps and benthic samples in Wales to look at limits of dispersal of Ephemeroptera, Plecoptera and Trichoptera. They found that near streams in which larvae had not been caught in 21 years, eight species from all three orders were caught, 
showing evidence for inter-catchment dispersal. They concluded that the results were sufficient to refute the dispersal hypothesis. Furthermore, Monteith et al. (2005) cited evidence from studies using stable isotope and molecular genetic techniques, which suggested that inter-catchment dispersal was much greater than it was hitherto thought to be. Overall, it can be concluded that there is little evidence that dispersal is a limiting factor that can explain differential recovery. The results from Monteith et al. (2005) concerning the Round Loch of Glenhead and Dargall Lane do, however, reinforce the findings of this study, namely that the waters arising from the Merrick-Mullwacher granitic intrusion show particularly poor biological recovery, in contrast to good chemical recovery.

\section{The "Community Closure" hypothesis}

This approach goes beyond a gross overview of species richness to examine the detailed composition of aquatic ecosystems before and after acidification. Specifically, it proposes that post-acidification ecosystems can achieve a new equilibrium which is resistant to the re-entry of Acid Sensitive species which were absent during the readjustment process. As proposed by Ledger and Hildrew (2005), shredder species (which feed on coarse organic matter) can take over the niches previously occupied by grazers (which consume finer material, and tend to be more Acid Sensitive). Supporting evidence includes the findings of Mackay and Kersey (1985) that acidic upland waters were dominated by shredders such as Plecoptera and had fewer grazers than circumneutral streams. Pretty et al. (2005) found that species-specific production of four species of shredder Plecoptera in an acid stream was high, and suggested that this could be explained by competitor release (that is, niche expansion in the absence of a competitor: Begon et al., 1986). The community closure model would also explain the findings of Bradley and Ormerod (2002), that Acid Sensitive species were found near previously acidified streams but failed to become established.

Ledger and Hildrew (2005) suggested that Nemourid and Leuctrid Plecoptera, in particular, might be able to adapt to a grazing mode, while in normal (non-acidic) conditions all Plecoptera except Amphinemoua sulciolis and Brachyptera risi can be categorized as shredders. In contrast, all Ephemeroptera are grazers.

The results of the present study, summarized in Table 7, show that the three granitic sites $\left(\mathrm{G}_{\mathrm{L}}, \mathrm{G}_{\mathrm{M}}, \mathrm{G}_{\mathrm{H}}\right)$ and the most afforested Sedimentary site $\left(\mathrm{S}_{\mathrm{H}}\right)$ had, in general, a lower proportion of grazer species compared to shredder species. However, these streams had low overall macroinvertebrate abundance (in terms of numbers of species and individuals); in contrast, the $\mathrm{S}_{\mathrm{H} \text { and }} \mathrm{S}_{\mathrm{M}}$ sites, which had higher abundance and showed a good level of recovery, had more balanced ratios of grazer species to shredder species. This would suggest that once biological recovery was underway, grazer species were able to recolonise these ecosystems, for instance by flight as adults or stream drift when immature (Thornton, 2008). Moreover, as Ephemeroptera (which are grazers) had more AS species than Plecoptera (mostly shredders), the paucity of grazers in the granitic and highly afforested streams can be explained by the possibility that these waters were more acidified initially. The community closure proposal can explain the relative paucity of some species, but not the very low levels of biological recovery found in four of the six sites. 
Table 7. Number of shredder and grazer species of Plecoptera and Ephemeroptera found at each site. (Note that all Plecoptera species which were present, other than Amphinemoua sulciolis, were categorised as shredders; all Ephemeroptera were categorised as grazers.)

\begin{tabular}{c|c|c|c}
\hline Site & Site designation & $\begin{array}{c}\text { Number of shredder } \\
\text { species }\end{array}$ & $\begin{array}{c}\text { Number of grazer } \\
\text { species }\end{array}$ \\
\hline Pulnabrick Burn & $\mathrm{G}_{\mathrm{L}}$ & 1 & 2 \\
Pulnagashel Burn & $\mathrm{G}_{\mathrm{M}}$ & 4 & 0 \\
Torr Lane & $\mathrm{G}_{\mathrm{H}}$ & 2 & 1 \\
Rowantree Burn & $\mathrm{S}_{\mathrm{L}}$ & 4 & 3 \\
Minnoch Tributary & $\mathrm{S}_{\mathrm{M}}$ & 3 & 2 \\
Black Burn & $\mathrm{S}_{\mathrm{H}}$ & 2 & 1 \\
\hline
\end{tabular}

There are other variations of this model, which consider various ecosystem parameters. For instance, Arnott et al. (2006) suggested that acidification changes the nature of predator assemblages high in the food chain, thus providing predator release for organisms lower at lower trophic levels.

This community closure hypothesis is of recent origin and illustrates the increasing complexity of explanatory models of recovery from acidification. However, community closure by itself cannot explain the substantial differential between chemical and biological recovery, nor can it explain the results of this study, showing that recovery was inhibited in granitic and highly afforested sites.

\section{The "episodicity" hypothesis}

This hypothesis does explain, however, the chemical-biological recovery differential. The central focus of this proposal is that fluctuations in upland stream conditions can be very large, with low-frequency but high-impact events (such as storms or rapid snow melt) having a disproportional impact on biological recovery, preventing recolonisation of AS species, while having less effect on mean chemical indicators (Kowalik and Ormerod, 2006).

The importance of rapid fluctuations in precipitation in aquatic acidification has long been recognized. Cresser and Edwards (1987), for instance, explain in detail how upland catchments are often steep with shallow soils, so that heavy rain, that quickly saturates the soil, would soon result in rapid lateral flow into watercourses, so that stream discharge would rise very rapidly. Under such conditions, common in mountain storms, water will have little time (a few hours) to be buffered within the soil; accordingly, stream acidity can increase markedly. SEPA (1996) reports that $\mathrm{pH}$ levels can change by a level of 2 over a matter of a few hours: that represents a hundred-fold increase in acidity. Accordingly, while some streams may show that overall, mean levels of acidification have fallen to normal, pristine conditions, there may be infrequent but extreme events, which are preventing biological recovery. Hall et al. (1980) reported evidence from studies of experimentally acidified waters that showed that the drift rates (that is, number of invertebrates moving from their usual benthic locations and into the water column, thus drifting downstream) increased markedly in AS species during high acidification. Furthermore, high flow rates (such as floods) will tend to flush out many benthic invertebrates, whether the conditions are acidic or not (Dobson and Frid, 1998; Thornton, 2008). 
A number of recent studies have provided evidence for the importance of such extreme events. Helliwell et al. (2007) found marked seasonality in their survey of nitrate levels and acidity in four upland areas of UK, including Galloway. Lepori and Ormerod (2005) reported that in episodically acidified streams survival (of species of Acid Sensitive Ephemeroptera) was the same as with matched circumneutral streams during periods of low flow, but substantially lower during episodes of high flow (during Alpine spring floods), when acidity increased significantly. Kowalik and Ormerod (2006) tested this idea experimentally, exposing one AS species of Ephemeroptera (Baetis rhodani) to either chronic exposure to acidification or repeated short-term (episodic) doses. Mortality was high under chronic exposure conditions (> 80\%), as compared to less than $10 \%$ mortality in a control group, maintained in circumneutral conditions. Those exposed to short-term episodes $(2 \times 4$ days, interspersed with 4 day recovery periods), however, also showed higher mortality (>40\%) than the controls. The authors further argue that many AS species have life cycles that render them particularly vulnerable to acidic episodes that would occur during high flow conditions in autumn and winter. They conclude by arguing that this evidence further supports the importance of episodic acidification. Kowalik et al. (2007) provided further evidence, showing that invertebrate assemblages were significantly different in sites that showed evidence of different types of episodic events.

There is, therefore, accumulating evidence for the significance of acidic episodes. In particular, streams may differ in the extent to which they are prone to high-flow acidic episodes. Factors involved in such differentiation may include aspect, slope, catchment size and altitude.

From the above summary of the literature and the evidence from this study, the "linearity" and "chemical threshold" explanations can be discounted: chemical recovery has proceeded too far for these to be important. The remaining hypotheses all have some supporting evidence, and it can be proposed that they may be acting together, in a complex fashion, to influence differentials in recovery. For instance, acidic episodes (which may be more common in some streams because of specific topographic features) may remove certain AS species during high flow events; some of these species may later recolonise those streams more slowly than others, because of differential dispersal methods and on arrival at their previous locations may not be able to re-establish because of community closure. Moreover, these factors may interact with geology and land-use. For instance, the acidifying effects of high-flow episodes may be considerably mitigated in sedimentary catchments if they are large enough; Adult Ephemeroptera may disperse shorter distances in afforested areas. It seems, therefore, that recovery from acidification, particularly with respect to biota, is considerably more complex than hitherto thought. The present study has attempted to conduct a controlled experiment of two of the contributory factors.

\section{Conclusions}

The results of this study show that some upland streams show very little biological recovery from acidification, although water chemistry has returned to nearly normal level. Moreover, those streams most affected are those with granitic bedrock and high levels of coniferous afforestation. There is statistical evidence that underlying geology might be more significant than land-use in retarding the reintroduction of Acid Sensitive species of macroinvertebrates. The factors do interact, however. Streams with 
sedimentary geology and lower levels of afforestation showed good chemical and biological recovery.

These results have been discussed in relation to a number of possible explanatory theories. It seems likely that differential dispersal, community closure and episodicity all contribute to the causes of differential chemical-biological recovery. Moreover, each might interact further with geology and afforestation. There are, furthermore, other factors, which may contribute to this complex picture, which have not been fully explored, such as topography, local vegetation and coniferous tree species. In can be concluded the process of recovery from acidification might be more complex than has been anticipated. There is, however, clear evidence that even with the substantial improvement in emissions quality in Europe, and the consequent decline in acidifying emissions, some aquatic ecosystems are - and are likely to remain - considerably damaged. Changes in land-use practices, some of which have already been initiated (such as leaving streams sides clear of replanting) may go some way to mitigate the problem. The results of this study, however, which show the importance of geology in limiting the recolonisation of AS species, indicated that geologically sensitive areas (such as much of Galloway) are unlikely to fully recover in the near future, if ever.

Global acid emissions continue to rise. There is also increasing concern that some areas are reaching Nitrogen saturation, where even small increases in deposition may have disproportionately large acidifying effects. Moreover, there is concern that climate change may contribute to reversing recovery from acidification in some cases (SEPA, 2006; Durance and Ormerod, 2007). Clearly, the impact of acidification on aquatic ecosystems is an issue of some complexity and continuing relevance.

Acknowledgements. The author gratefully acknowledges the help of Dr. Ralph Kirkwood and Dr. Helen Keenan of the David Livingstone Centre for Sustainability, University of Strathclyde and also to the Forestry Commission Scotland for providing access to the study sites and information on land-use. This study was financed by a University of Strathclyde Collaborative Training Account.

\section{REFERENCES}

[1] Alewell, C., Manderscheid, B., Meesenburg, H., Bittersohl, J. (2000): Is acidification still an ecological threat? - Nature 407: 856-857.

[2] Armbruster, M., Abiy, M., Feger, K.H. (2003): The biogeochemistry of two forested catchments in the Black Forest and the eastern Ore Mountains (Germany). Biogeochemistry 65: 341-368.

[3] Arnott, S.E., Jackson, A.B., Alarie, Y. (2006): Distribution and potential effects of water beetles in lakes recovering from acidification. - Journal of the North American Benthological Society 25: 811-824.

[4] Begon, M., Harper, J.L., Townsend, C.R. (1986): Ecology (2nd. ed). - Blackwell, Boston.

[5] Beverland, I.B., Crowther, J.M., Srinivas, M.S.N. (1997): Episodic nature of wet deposition of acidic material in a site in South-East England. - Water, Air and Soil Pollution 96: 73-91.

[6] Bouwman, A.F., Van Vuuren, D.P., Derwent, R.G., Posch, M. (2002): A global analysis of acidification and eutrophicationof terrestrial ecosystems. - Water, Air and Soil Pollution 141: 349-382.

[7] Bradley, D.C., Ormerod, S.J. (2002): Long-term effects of catchment liming on invertebrates in upland streams. - Freshwater Biology 47: 161-171. 
[8] Clair, T.A., Hindar, A. (2005): Liming for the mitigation of acid rain effects in freshwaters: a review of recent results. - Environmental Reviews 13: 91-128.

[9] Collen, P., Harriman, R. Morrison, R.B.S. Keay, E.J.,Watt, A.W. (2000): Restoration of a brown trout (Salmon trutta L.) population to Loch Enoch, an acidified loch in Galloway, south-west Scotland. - Freshwater Forum 14: 3-14.

[10] Colls, J. (2002): Air Pollution. $-2^{\text {nd }}$ ed., Taylor and Francis, London.

[11] Cresser, M., Edwards, A. (1987): Acidification of Freshwaters. - CUP, Cambridge.

[12] Csontos, P., Halbritter, A., Tamás, J., Szili-Kovács, T., Kalapos, T., Uzinger, N., Anton, A. (2012): Afforestation of dolomite grasslands with non-native Pinus nigra in Hungary and its effect on soil trace elements. - Applied Ecology and Environmental Research 10(4): 405-415.

[13] Davies, J.J.L., Jenkins, A., Monteith., D.T. Evans, C.D., Cooper, D.M. (2005): Trends in surface water chemistry of acidified UK Freshwaters 1988-2002. - Environmental Pollution 137: 27-39.

[14] Dobson, M., Frid, C. (1998): Ecology of Aquatic Systems. - Longman, Harlow.

[15] Doughty, C.D. (1990): Acidity in Scottish Rivers. - Scottish River Purification Board, East Kilbride.

[16] Durance, I., Ormerod, S.J. (2007): Climate change effects on upland stream macroinvertebrates over a 25 year period. - Global Change Biology 13: 942-957.

[17] Elliott, J.M., Humpesch, U.H., Macan, T.T. (1988): Larvae of the British Ephemeroptera: a key with ecological notes. - Freshwater Biological Association, Ambleside.

[18] Environment Resources Management (2000): The Galloway Local Forestry Framework. - ERM, Edinburgh.

[19] Forestry Commission (2003): Forests and Water Guidelines. - 4th. ed., Forestry Commission, Edinburgh.

[20] Gagkas, Z., Heal, K.V., Stuart, N., Nisbet, T.R. (2008): Effects of broadleaf woodland cover on streamwater chemistry and risk assessments of streamwater acidification in acidsensitive catchments in the UK. - Environmental Pollution 154: 232-240.

[21] Greig, D.C. (1971): British Regional Geology - The South of Scotland. - 3rd ed., Edinburgh, HMS0.

[22] Hall, R.J., Waters, T.F., Cook, E.F. (1980): The Role of Drift Dispersal in Production Ecology of a Stream Mayfly. - Ecology 61: 37-43.

[23] Harriman, R., Watt, A.W., Christie, A.E.G., Moore, D.W., McCartney, A.G., Taylor, E.M. (2003): Quantifying the effects of forestry practices on the recovery of upland streams and lochs from acidification. - The Science of the Total Environment 310: 101111.

[24] Helliwell, R.C., Davies, J.J., Evans, C.D., Jenkins, A., Coull, M.C., Reynolds, B., Norris, D., Ferrier, R.C. (2007): Spatial and seasonal variations in nitrogen leaching and acidity across four acid-impacted regions of the UK. - Water, Air \& Soil Pollution 185(1): 3-19.

[25] Hynes, H.B.N. (1977): Adults and nymphs of British Stoneflies (Plecoptera). - 3rd. ed., Freshwater Biological Association, Ambleside.

[26] Jamieson, A. (1998): A comparative study of Acid Rain, afforestation and freshwater acidification. - M.Sc. Thesis, University of Strathclyde, Glasgow.

[27] Jenkins, A., Helliwell, R.C., Swingewood, P.J., Sefton, C. Renshaw, M., Ferrier, R.C. (1998): Will reduced sulphur emissions under the Second Sulphur Protocol lead to recovery of acid sensitive sites in UK? - Environmental Pollution 99: 309-318.

[28] Johnson, D.W., Cresser, M.S., Nilsson S.I., Turner, J., Ulrich, B., Binkley D., Cole, D.W. (1991): Soil Changes in forest ecosystems: evidence for and probable causes. Proceedings of the Royal Society of Edinburgh 97B: 81-116.

[29] Johnson, R.K., Angeler, D.G. (2010): Tracing recovery under changing climate: response of phytoplankton and invertebrate assemblages to decreased acidification. - Journal of the North American Benthological Society 29(4): 1472-1490. 
[30] Kimmins, D.E. (1950a): Handbook for the Identification of British Insects: Ephemeroptera. - Royal Entomological Society, London.

[31] Kimmins, D.E. (1950b): Handbook for the Identification of British Insects: Volume 1, part 6: Plecoptera. - Royal Entomological Society, London.

[32] Kowalik, R.A., Ormerod, S.J. (2006): Intensive sampling and transplantation experiments reveal continued effects of episodic acidification on sensitive stream invertebrates. Freshwater Biology 51: 180-191.

[33] Kowalik, R.A., Cooper, D.M., Evans, C.D., Ormerod, S.J. (2007): Acidic episodes retard the biological recovery of upland British streams from chronic acidification. - Global Change Biology 13: 2439-2452.

[34] Ledger, M.E., Hildrew, A.G. (2005): The ecology of acidification and recovery: changes in herbivore-algal food web linkages across a stream $\mathrm{pH}$ gradient. - Environmental Pollution 37: 103-118.

[35] Lepori, F., Ormerod, S.J. (2005): Effects of spring acid episodes on macroinvertebrates revealed by population data and in situ toxicity tests - Freshwater Biology 50: 15681577.

[36] Lovett, G.M., Tear, T.H., Evers, D.C., Findlay, S.E.G., Cosby, B.J., Dunscomb, J.K. Driscoll, C.T., Weathers, K.C. (2009): Effects of Air Pollution on Ecosystems and Biological Diversity in the Eastern United States. - Annals of the New York Academy of Sciences 1162: 99-135.

[37] Macan, T.T. (1959): A guide to freshwater invertebrate animals. - Longman, London.

[38] Mackay, R.J., Kersey, K.E. (1985): A preliminary study of aquatic insect communities and leaf decomposition in acid streams near Dorset, Ontario. - Hydrobiologia 122: 3-11.

[39] Mason, C.F. (1991): Biology of freshwater pollution. - Longman, Harlow.

[40] Masters, Z., Peteresen, I., Hildrew, A.G., Ormerod, S.J. (2007): Insect dispersal does not limit the biological recovery of streams from acidification. - Aquatic Conservation: Marine and Freshwater Ecosystems 17: 375-383.

[41] Matsubara, H., Morimoto, S., Sase, H., Ohizumi, T., Sumida, H., Nakata, M. and Ueda, H. (2009): Long-Term Declining Trends in River Water pH in Central Japan. - Water Air Soil Pollution 200:253-265.

[42] Monteith D. T. and Evans, (2005): Recovery from acidification in the UK: Evidence from 15 years of acid waters monitoring. - Environmental Pollution 137: 3-13.

[43] Monteith, M.T., Hildrew, W.R.B., Flower, R.J., Raven, P.J., Beaumont, W.R.B., Collen, P., Kreiser, A.M., Shilland, E.M., Winterbottom, J.H. (2005): Biological responses to the chemical recovery of acidified fresh waters in the UK. - Environmental Pollution 137: 83-101.

[44] Pretty, J.L., Giberson, D.J., Dobson, M. (2005): Resource dynamics and detritivore production in an acid stream. - Freshwater Biology 50: 578-591.

[45] Puhr, C.B., Donoghue, D.N.M., Tervet, D.J., Sinclair, C. (2000): Regional patterns of streamwater acidity and catchment afforestation in Galloway, SW Scotland . - Water, Air and Soil Pollution 120: 47-70.

[46] Quigley, M. (1977): Invertebrates in Streams and Rivers: A key to identification. Edward Arnold, London.

[47] Raddum, G.R., Fjellheim, A. (2002): Species composition of freshwater invertebrates in relation to chemical and physical factors in high Mountains in soutwestern norway. Water, Air And Soil Pollution Focus 2: 311-328.

[48] Rendall, D., Bell, A. (2008): Current Acidification status and evidence of recovery in some Dumfries and Galloway watercourses. - SEPA ecology report DF08/01., SEPA, Stirling.

[49] Schindler, D.W. (1988): Effects of Acid Rain on Freshwater Ecosystems. - Science 239: 149-157.

[50] SEPA (Scottish Environmental Protection Agency) (2006): State of Scotland's Environment 2006. - SEPA, Stirling. 
[51] Thornton, D.P. (2008): Macroinvertebrate stream drift - an Australian example. Applied Ecology and Environmental Research 6(1): 49-55.

[52] UKAWMN (2001): The United Kingdom Acid Waters Monitoring Network. - DETR, London.

[53] Wei, H., Wang, J.L. (2005): Characteristics of acid rain in Jinyun mountain, Chongqing, China. - Applied Ecology and Environmental Research 3: 29-37.

[54] Wellburn, A. (1988): Air pollution and acid rain: the biological impact. - Longman, Harlow. 